\title{
Peroneus Longus Tendon Regeneration after Anterior Cruciate Ligament Reconstruction with Magnetic Resonance Imaging Evaluation
}

\author{
Sholahuddin Rhatomy ${ }^{1,2 *}$, Bambang Kisworo ${ }^{3}$, Bunarwan Prihargono ${ }^{4}$, Faiz Alam Rashid ${ }^{1}$, Nolli Kressoni ${ }^{5}$ \\ ${ }^{1}$ Department of Orthopaedics and Traumatology, Dr. Soeradji Tirtonegoro General Hospital, Klaten, Indonesia; ${ }^{2}$ Department \\ of Orthopaedics and Traumatology, Faculty of Medicine, Public Health and Nursing, Universitas Gadjah Mada, Yogyakarta, \\ Indonesia; ${ }^{3}$ Department of Orthopaedics and Traumatology, Panti Rapih Hospital, Yogyakarta, Indonesia; ${ }^{4}$ Department of \\ Orthopaedics and Traumatology, Karanganyar General Hospital, Karanganyar, Indonesia; ${ }^{5}$ Department of Radiology, Indriati \\ Hospital, Sukoharjo, Indonesia
}

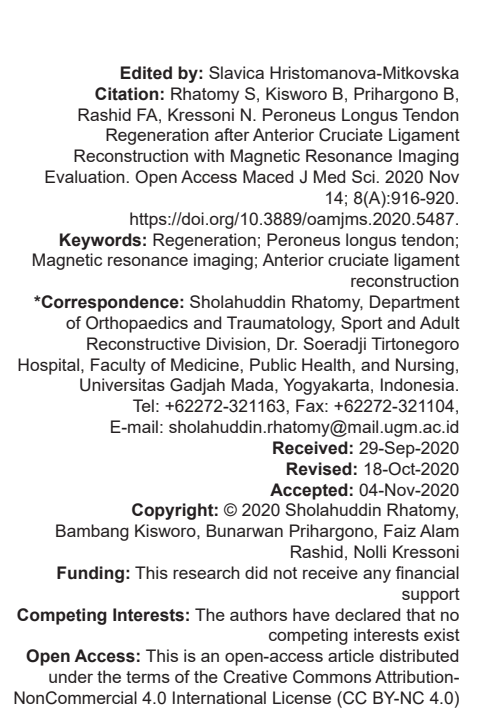

\section{Abstract}

BACKGROUND: Peroneus longus graft can be recommended as a superior graft over hamstring in anterior cruciate ligament $(\mathrm{ACL})$ reconstruction. There are many studies concerning hamstring tendon regeneration, but there are few studies on the regeneration of the peroneus longus tendon after ACL reconstruction.

AIM: This study aimed to investigate whether regeneration of the peroneus longus tendon occurs after ACL reconstruction with magnetic resonance imaging

METHODS: Twenty-five patients underwent ACL reconstruction with donors from the peroneus longus tendon by the same operator and were followed 12 months later with bilateral crural magnetic resonance imaging (MRI) for comparison of the donor and healthy peroneus longus tendon areas. Regeneration was assessed at $5 \mathrm{~cm}, 10 \mathrm{~cm}$, and $15 \mathrm{~cm}$ from the ankle joint.

RESULTS: The average age 30.4 (18-38) years old. There were 17 right and 8 left knees involved in this study. The interval between surgery and MRI was 1 year. The average regeneration presentation was located in the distal part ( $5 \mathrm{~cm}$ from the ankle joint) $66.78 \%$, medial part (10 cm from the joint) $63.2 \%$, and proximal part (15 cm from the ankle joint) $67.53 \%$. There was no significant difference in the presentation of proximal, medial, and distal areas while there was a significant difference between age and regeneration of the proximal area, $p<0.05(p=0.047)$. Tissue regeneration was tendinous and it appeared smaller in the place where the tendons grew.

CONCLUSION: Regeneration of the peroneus longus tendon occurred after ACL reconstruction at a 1-year follow-up according to MRI.

\section{Introduction}

Anterior cruciate ligament $(A C L)$ is one of the few ligaments in the knee that is often injured in sports and accidents. The incidence of ACL rupture is higher in women than in men. ACL reconstruction is a common surgical procedure for ACL rupture in active people. The purpose of $A C L$ reconstruction is to restore knee stability, relieve pain and instability symptoms, and return the patient to daily activities [1]. There are several graft choices used in ACL reconstruction, one of which is the peroneus longus tendon graft [2]. Peroneus longus autograft is an effective and safe graft as an alternative to $A C L$ reconstruction [3]. In biomechanical studies, there are similarities in tensile strength between the hamstring and peroneus longus tendon [4]. Rhatomy et al. in their study confirmed that the peroneus longus graft can be recommended as a superior graft over hamstring in a single bundle $A C L$ reconstruction because the peroneus longus has a graft with a larger diameter, less hypotrophy, and better ankle function compared to hamstring tendons [5]. Otis et al. in his study explained the peroneus longus muscle is an evertor muscle that is less effective than the peroneus brevis. Nevertheless, the ankle function for eversion is still good at the donor site [6]. Morbidity at the donor site of peroneus longus was reported to occur within 1 year after surgery. It can be in the form of sensory, tissue, and structural problems, so ankle muscle rehabilitation after surgery is required [7]. Mervyn et al. reported regeneration of the hamstring tendon after ACL surgery in the form of growth at a location near the anatomic position which was functional [8]. Regeneration in gracilis and semitendinosus tendons also occurs distally from the 
joint line [9]. Magnetic resonance imagery (MRI) can be a parameter to assess the regeneration of peroneus longus tendon grafts in ACL reconstruction [10], [11]. Accordingly, a deeper study of the regeneration of the peroneus longus graft in ACL reconstruction is needed. This study aimed to investigate whether regeneration of the peroneus longus tendon occurs after $A C L$ reconstruction with MRI.

\section{Materials and Methods}

Twenty-five patients underwent single-bundle $A C L$ reconstruction using peroneus longus tendon graft between June and December 2018. We analyzed the cohort prospectively for this study. The inclusion criteria for the patients were ACL rupture without other ligament rupture, meniscus intact, and there is no cartilage defect. Those with other ligament rupture, meniscal injury, chondral lesion, any deformity of the lower limb, or associated fracture in the lower extremity were excluded from the study. We diagnosed $A C L$ rupture through clinical assessment (Lachman test, anterior drawer test, or Lelli test), and MRI.

All subjects were informed about their knee condition and treatment procedures. All the arthroscopic procedures were done by one experienced surgeon. Patients received a comprehensive clinical assessment and radiological examination before their operation and MRI 1 year follow-up to evaluate the regeneration of peroneus longus.

For the first part of this study, MRI was performed to see the regeneration of the peroneus longus in the 12 months after ACL reconstruction. The patient underwent $\mathrm{MRI}$ on both legs at 12 months postoperatively, then the areas were compared between the donor and healthy sites. Crural MRI was made from the ankle joint to the knee joint. MRI was assessed in 3 axial sections, which were proximal $(15 \mathrm{~cm}$ from the ankle joint), media (10 $\mathrm{cm}$ from the ankle joint), and distal $(5 \mathrm{w} \mathrm{cm}$ from the ankle joint). All patients were operated on by the same orthopedic doctor, then they were rehabilitated with a standard brace. This study was approved by the medical and health research ethics committee with reference number KE/FK/FK/210/2018.

\section{Arthroscopic surgery technique}

Operations were done by the same operator. Locations for the skin incision were marked at 2-3 cm above and $1 \mathrm{~cm}$ behind the lateral malleolus. The incision was made across the skin, subcutaneous tissue, and superficial fascia. Peroneus longus and brevis tendons were then identified. The location of this tendon was marked $2-3 \mathrm{~cm}$ above the level of the lateral malleolus. The distal end from the peroneus longus tendon to the peroneus brevis tendon was sewn with end to side sutures. Peroneus longus was proximally released with a tendon stripper at $4-5 \mathrm{~cm}$ from the fibular head to prevent injury to the peroneal nerve.

\section{Statistical analysis}

Statistical analysis was performed using SPSS 16.0. Distribution of the data was assessed using Shapiro-Wilk tests. Comparison of proximal, medial and distal tendon regeneration area was analyzed using ANOVA (Bonferroni test as post hoc test). The results were calculated as mean with standard deviation (SD), with $p<0.05$ as a significant value.

\section{Results}

This study group consisted of 21 men and 4 women. The average age of the patients at the time of MRI was 30.4 (18-38) years old. There was 17 right and 8 left knees involved in this study. The interval between surgery and MRI was 1 year. The patients had an intact meniscus. In all patients, regeneration of the peroneus tendon varied.

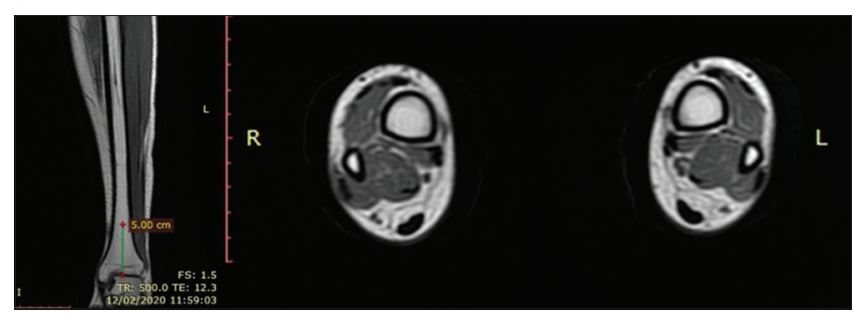

Figure 1: Magnetic resonance imaging axial view $5 \mathrm{~cm}$ from ankle joint

The average regeneration presentation was distal (5 cm from the ankle joint) $66.78 \%$ (Figure 1), medial (10 cm from the ankle joint) $63.2 \%$ (Figure 2), and proximal (15 cm from the ankle joint) $67.53 \%$ (Figure 3 and Table 1). Based on the Shapiro-Wilk test with $(n=15) p>0.05$ (distal $p=0.235$, medial $p=0.156$, and proximal $p=0.735)$, the data were normally distributed. Based on one-way ANOVA, sex was not significantly related to regeneration $(p>0.05)$ (Table 2). There were no significant differences in the proximal, mid, and distal areas (Table 1).

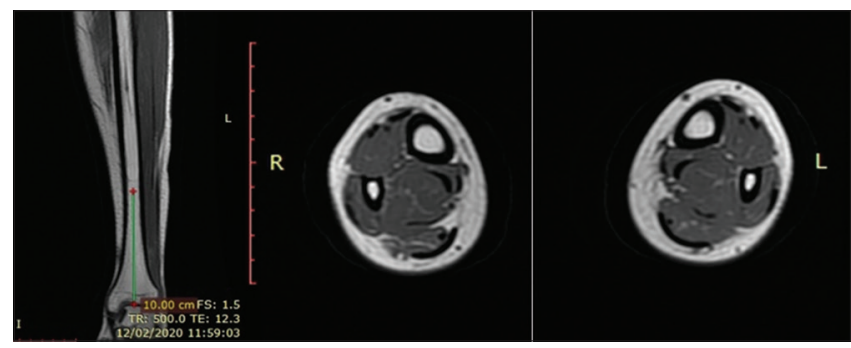

Figure 2: Magnetic resonance imaging axial view $10 \mathrm{~cm}$ from ankle joint 


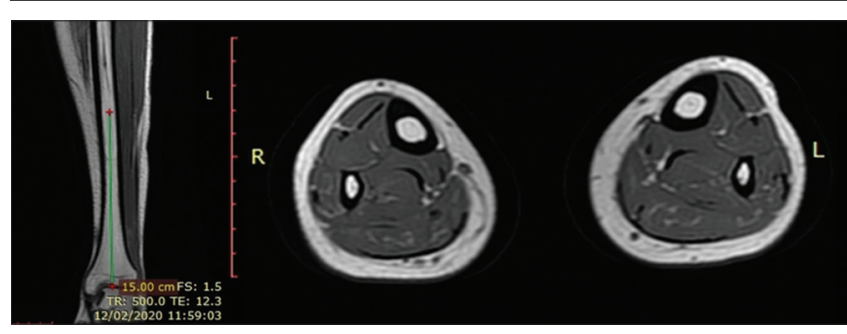

Figure 3: Magnetic resonance imaging axial view $15 \mathrm{~cm}$ from ankle joint

Tissue regeneration was tendinous and it appeared smaller in the place where the tendons grew (Figure 4).

Table 1: Percentage of regeneration

\begin{tabular}{lll}
\hline Location & Percentage of regeneration (mean \pm SD) & p-value \\
\hline $5 \mathrm{~cm}$ (distal) & $66.78 \pm 1.29$ & 0.235 \\
$10 \mathrm{~cm}$ (medial) & $63.2 \pm 1.21$ & \\
$15 \mathrm{~cm}$ (proximal) & $67.53 \pm 1.84$ & \\
\hline
\end{tabular}

\section{Discussion}

In this study, the results showed that peroneus longus tendon regeneration occurred after ACL graft reconstruction. This finding is consistent with previous research on the regeneration of hamstring tendons. Rhatomy et al., in a previous study with 6 months of follow-up of the peroneus longus tendon, stated that there was no impairment in ankle stability and there were a good ROM and good outcome. Peroneus tendons are an alternative to reconstructing ligaments to prevent morbidity from donor sites in another tendon [5].

Table 2: Percentage of regeneration according to sex

\begin{tabular}{llll}
\hline Location & Sex & Percentage of regeneration (mean \pm SD) & p-value \\
\hline $5 \mathrm{~cm}$ (distal) & Male & $67.22 \pm 13.84$ & 0.747 \\
& Female & $63.89 \pm 2.38$ & \\
$10 \mathrm{~cm}$ (medial) & Male & $65.2 \pm 11.54$ & 0.102 \\
& Female & $50.18 \pm 6.6$ & \\
$15 \mathrm{~cm}$ (proximal) & Male & $70.77 \pm 17.23$ & 0.081 \\
& Female & $46.47 \pm 12.59$ & \\
\hline
\end{tabular}

Kerimoglu studied 12 patients who underwent $A C L$ reconstruction using peroneus longus tendon grafts with follow-up ranging from 18 to 96 months using MRI and found that there was a regeneration of peroneus longus tendons and there was no disturbance in ankle function and exercise [11].

Rob et al. in his study of 22 patients who underwent MRI follow-up at the location of the hamstring after ACL reconstruction for 2 weeks, 6 months, and 12 months stated that there was a regeneration of hamstring tendons [9]. A study by Mervyn et al. of 225 patients who underwent $A C L$ reconstruction with hamstring tendons and follow-up after 6 months using MRI revealed the semitendinosus and gracilis tendons could grow close to their anatomic and functional positions [8]. Nakamae in his study reported that there were 2 cases of hamstring tendon regeneration after $A C L$ reconstruction due to re-rupture during regeneration [12].

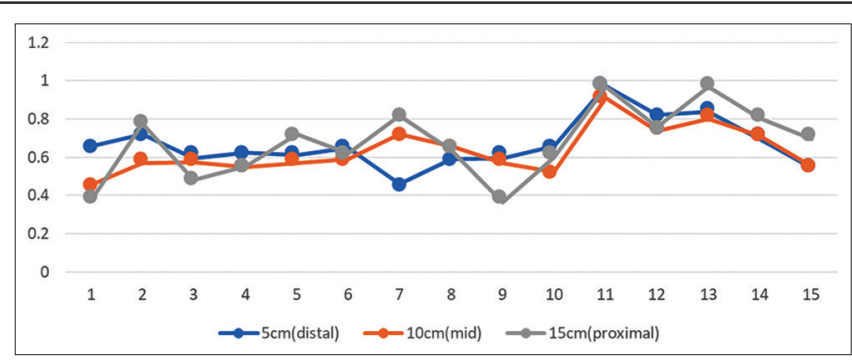

Figure 4: Difference in comparison of the peroneus longus size from donor site and peroneus longus tendon of the contralateral side

Suijkerbuijk, in a study with a systematic review of hamstring tendon regeneration, said the majority had regeneration at $50-100 \%$ in semitendinosus tendons and $46-100 \%$ in gracilis tendons 1 year after ACL reconstruction [13]. However, hamstring tendons in the elderly and smokers had reduced regeneration potential [14].

Other method to evaluate soft tissue regeneration with using ultrasonography (USG) or soft tissue biopsy. Bedi et al., in their study with dynamic $12 \mathrm{MHz}$ ultrasonography, assessed the ipsilateral and contralateral areas from 15 patients who underwent hamstring tendons $A C L$ reconstruction. There was tissue growing at the site where the graft was taken, proximal retraction from the musculotendinous junction, and tissue disorganization which did not show the same physiological function as the original tendon [15]. A prospective study by Papandrea et al. involving 40 patients who underwent $A C L$ reconstructions with hamstring graft tendon followed by pre- and postoperative assessment using ultrasound at 2 weeks to 24 months postoperatively showed that semitendinosus regeneration was similar to normal tendons within 18 months post-month ACL reconstructive surgery [16]. Papalia et al., in a systematic review of 19 articles with a total of 400 observed patients, stated that the average soft tissue regeneration was found in $86 \%$ of hamstring tendon after $\mathrm{ACL}$ reconstruction and $74 \%$ from the biopsy of cases with typical histology with tendons [17].

Eriksson et al. stated in his study of 11 patients with 6-12 months follow-up for ACL reconstruction that regeneration of hamstring grafts was found in 8 patients using MRI 6 months postoperatively. The regeneration of the semitendinosus and gracilis tendons with the topography of the joints was normal. MRI could not be used to distinguish regeneration from tendons or scar tissue. Therefore, Eriksson conducted another study on this matter. In a subsequent study, Eriksson et al. conducted a study of 6 patients between 7 and 28 months after ACL reconstruction who were assessed by $\mathrm{MRI}$, open surgery, and histological biopsy. There was regeneration for semitendinosus and gracilis tendons macroscopically with open surgery and histologically at 28 months follow-up [18]. The tendon resembled normal tendon in terms of appearance and tensile strength. Results obtained histologically showed that the tendon consisted of collagen structures separated 
by small fibroblast cells that are uniform like normal tendons; there was an increase in the proliferation of fibroblasts and capillaries [18], [19], [20], [21].

Limitations of this study are limited subject and short-term follow-up, further study needed to prove the regeneration using dynamic sonography or dynamic $\mathrm{MRI}$, and study in animal to evaluate regeneration using histology finding. In this study, MRI finding showed that regeneration of peroneus longus tendon was likely to occur within 1 year.

\section{Conclusion}

Good peroneus longus tendon regeneration was observed on MRI after 1 year.

\section{Acknowledgments}

We would like to thank Erik Christopher with his help during manuscript preparation

\section{Ethical approval}

The informed consent form declared that patient data or samples will be used for educational or research purposes. Our institutional review board also provided ethical approval in the form of case report with $\mathrm{KE} / \mathrm{FK} / \mathrm{FK} / 210 / 2018$ as the protocol number.

\section{References}

1. Rhatomy S, Tanzil H, Setyawan R, Amanda C, Yuarno K, Rukmoyo $\mathrm{T}$, et al. Influence of anthropometric features on peroneus longus graft diameter in anterior cruciate ligament reconstruction: A cohort study. Ann Med Surg (Lond). 2019;48:77-80. https://doi.org/10.1016/j.amsu.2019.10.023 PMid:31737263

2. Kerimoğlu S, Aynaci $O$, Saraçoğlu M, Aydin H, Turhan AU. [Anterior cruciate ligament reconstruction with the peroneus longus tendon]. Acta Orthop Traumatol Turc. 2008;42(1):38-43. https://doi.org/10.3944/aott.2008.42.1.038 PMid:18354276

3. Shi F, Hess DE, Zuo J, Liu S, Wang X. Peroneus longus tendon autograft is a safe and effective alternative for anterior cruciate ligament reconstruction. J Knee Surg. 2019;32(8):804-11. https://doi.org/10.1055/s-0038-1669951 PMid:30206913

4. Mustamsir E, Yuarno K. Tensile strength comparison between peroneus longus and hamstring tendons: A biomechanical study. Int J Surg Open. 2017;9:41-4. https://doi.org/10.1016/j.

\section{ijso.2017.10.002}

5. Rhatomy S, Asikin Al, Wardani AE, Rukmoyo T, LumbanGao I, Budhiparama NC. Peroneus longus autograft can be recommended as a superior graft to hamstring tendon in single-bundle ACL reconstruction. Knee Surg Sports Traumatol Arthrosc. 2019;27(11):3552-9. https://doi.org/10.1007/ s00167-019-05455-w

PMid:30877316

6. Otis JC, Ph D, Deland JT, Lee S, Gordon J. Peroneus brevis is a more effective evertor than peroneus longus abstract. Foot Ankle Int. 2004;25(4):242-6. https://doi. org/10.1177/107110070402500408

\section{PMid:15132932}

7. Zhao J, Huangfu X. The biomechanical and clinical application of using the anterior half of the peroneus longus tendon as an autograft source. Am J Sports Med. 2012;40(3):662-71. https:// doi.org/10.1177/0363546511428782

PMid:22174343

8. Cross MJ, Roger G, Kujawa P, Anderson IF. Regeneration of the semitendinosus and gracilis tendons following their transection for repair of the anterior cruciate ligament. Am J Sports Med. 1992;20(2):221-3. https://doi. org/10.1177/036354659202000223

PMid:1558254

9. Janssen RP, Van Der Velden MJ, Pasmans HL, Sala HA Regeneration of hamstring tendons after anterior cruciate ligament reconstruction. Knee Surg Sports Traumatol Arthrosc. 2013;21(4):898-905. https://doi.org/10.1007/ s00167-012-2125-0

PMid:22763570

10. Grassi A, Bailey JR, Signorelli C, Carbone G, Tchonang A, Lucidi GA, et al. Magnetic resonance imaging after anterior cruciate ligament reconstruction: A practical guide. World J Orthop. 2016;7(10):638-49. https://doi.org/10.5312/wjo. v7.i10.638

PMid:27795945

11. Kerimoğlu $S$, Koşucu $P$, Livaoğlu $M$, Yükünç I, Turhan AU, Magnetic resonance imagination of the peroneus longus tendon after anterior cruciate ligament reconstruction. Knee Surg Sports Traumatol Arthrosc. 2009;17(1):35-9. https://doi.org/10.1007/ s00167-008-0626-7

PMid:18818901

12. Nakamae A, Ochi M, Deie M, Adachi N. Unsuccessfu regeneration of the semitendinosus tendon harvested for anterior cruciate ligament reconstruction: Report of two cases. Orthop Traumatol Surg Res. 2012;98(8):932-5. https://doi. org/10.1016/j.otsr.2012.07.011

PMid:23123037

13. Suijkerbuijk MA, Reijman M. Hamstring tendon regeneration after harvesting: A systematic review. Am J Sports Med. 2015;43(10):2591-8. https://doi. org/10.1177/0363546514562169

PMid:25548149

14. Suijkerbuijk MA, Reijman M, Oei EH, Meuffels DE, Van Meer BL. Predictive factors of hamstring tendon regeneration and functional recovery after harvesting: A prospective follow-up study. Am J Sports Med. 2018;46(5):1166-74. https://doi. org/10.1177/0363546517751660 PMid:29420917

15. Bedi A, Srinivasan RC, Salata MJ, Downie B, Jacobson JA Edward M. Structural and functional analysis of the semitendinosus tendon after harvest for soft tissue reconstructive procedures: A dynamic ultrasonographic study. Knee Surg Sports Traumatol Arthrosc. 2013;21(3):606-14. https://doi.org/10.1007/s00167-012-1989-3 


\section{PMid:22476527}

16. Papandrea P, Vulpiani MC, Ferretti A, Conteduca F. Regeneration of the semitendinosus tendon harvested for anterior cruciate ligament reconstruction. Evaluation using ultrasonography. Am J Sports Med. 2000;28(4):556-61. https://doi.org/10.1177/0363 5465000280041901

PMid:10921650

17. Papalia R, Franceschi F, Adamio SD, Balzani LD. Hamstring tendon regeneration after harvest for anterior cruciate ligament reconstruction: A systematic review. Arthroscopy. 2015;31(6):1169-83. https://doi.org/10.1016/j.arthro.2014.11.015 PMid:25557918

18. Eriksson K, Larsson H, Wredmark T, Hamberg P. Semitendinosus tendon regeneration after harvesting for $\mathrm{ACL}$ reconstruction. $\mathrm{A}$ prospective MRI study. Knee Surg Sports Traumatol Arthrosc. 2001;7(4):220-5. https://doi.org/10.1007/s001670050152

PMid:10462211

19. Okahashi $K$, Sugimoto $K$, Iwai $M$, Oshima $M$, Samma M,
Fujisawa $\mathrm{Y}$, et al. Regeneration of the hamstring tendons after harvesting for arthroscopic anterior cruciate ligament reconstruction: A histological study in 11 patients. Knee Surg Sports Traumatol Arthrosc. 2006;14(6):542-5. https://doi. org/10.1007/s00167-006-0068-z

PMid: 16525795

20. Åhlén $M$, Lidén $M$, Rostgård L. Histological evaluation of regenerated semitendinosus tendon a minimum of 6 years after harvest for anterior cruciate ligament reconstruction. Orthop J Sports Med. 2014;2(9):2325967114550274. https://doi. org/10.1177/2325967114550274

PMid:26535362

21. Ferretti A, Conteduca F, Morelli F, Masi V. Regeneration of the semitendinosus tendon after its use in anterior cruciate ligament reconstruction: A histologic study of three cases. Am J Sports Med. 2002;30(2):204-7. https://doi.org/10.1177/036354650203 00021001

PMid:11912089 